\title{
Modelling and Controller Design for Temperature Control of Power Plant Heat Exchanger
}

\author{
Abdulrahman A.A.Emhemed ${ }^{1, *}$, Aleisawee Alsseid ${ }^{1}$, Dirman Hanafi ${ }^{2}$ \\ ${ }^{1}$ College of Electronic Technology-Bani Walid, 38645 Bani Walid, Libya \\ ${ }^{2}$ Faculty of Electrical and Electronic Engineering, Universiti Tun Hussein Onn Malaysia, 86400 Parit Raja, Malaysia
}

Copyright $\odot 2017$ by authors, all rights reserved. Authors agree that this article remains permanently open access under the terms of the Creative Commons Attribution License 4.0 International License

\begin{abstract}
Power Plant Heat exchanger is widely used in chemical and petroleum plants because it can sustain wide range of temperature and pressure. Heat exchanger is a high nonlinearity and poor dynamics plant; therefore it is complex to model and difficult to control its dynamics. In this paper two types of heat exchanger model and controller are applied for selecting suitable model and controller. First model is called (Physical model) and derived using real parameter of heat exchanger plant. Second, a Second Order Plus Dead Time (SOPDT model) that is derived from the response of heat exchanger. While the controllers are consisted of fuzzy proportional derivative (FPD) controller and proportional integral derivative (PID) controller and applied to the model and their responses are compared with the existing PID controller. The PID controller response based on Physical model gives similar response of existing PID controller based real heat exchanger plant in comparison with SOPDT model. That means the Physical model is able to represent the heat exchanger plant dynamics more accurately than SOPDT model. For the controller, the FPD control gives a slight enhancement based on SOPDT model. Therefore, FPD controller is more suitable than PID controller.
\end{abstract}

Keywords Power Plant Heat Exchanger, Modelling, Fuzzy Control, PID Control

\section{Introduction}

Advanced control of heat exchanger processes are important tasks for control engineers, as these devices belong to the key of equipment in petrochemical, food processing and pharmaceutical industries and they are energy intensive processes [1]. Many classical control techniques are performed on process control include PID, IMC-PID, and MRAC [2-6]. Most of the control systems in power stations adopted based on PID controller.
Unfortunately, large inertia and lag appeared by using PID controller which could not adjust the temperature accurately [7]. On the other hand, drawbacks of this system are terrible robustness and fixed PID parameter which could not regulate with variation of the object. Because there are nonlinearity, variation, disturbance and change of objective architecture, the system could not attain well result by using PID parameter which previously set [7][8].

The method called coefficient diagram method (CDM) based controller would be more suitable for handling nonlinear control problem than conventional PID. Also, CDM controller performance is more consistent in term of the peak magnitudes of the disturbance error [9]. Another technique, multiple model based Proportional integral derivative control (MM-PID) and multiplemodel based model reference adaptive control (MM-MRAC) applied for a nonlinear heat exchanger process. MM-MRAC designed on two techniques MM-MRAC with MIT rule and MM-MRAC with Lyapunov rule. MM-MRAC (MIT rule) performs better than MM-MRAC (Lyapunov) since it has better set point tracking [10]. In 2010, Technical report by Control Station, Inc. discussed the effect of Proportional $\mathrm{P}$ Control, Proportional Integral PI Control, and Proportional Integral Derivative PID Control on heat exchanger process real-time observation. Their study achieved superior enhancement for PI compared to P control. While the recommended tuning correlations for PID control is the Internal Model Control (IMC). Likewise, the control parameters extracted based on FOPDT heat exchanger model and Loop-Pro software is used for fitting the data. The method is easy, effective and thus, there is no wasted time or expense [11]. Robust strategy designed to observe the behaviour of Heat exchanger plant. PI-Ziegler Nichols (PI control) and H-Infinity (Robust control) are used for getting best sensitivity functions. The robust control reduced the overshoot compared to conventional PI control [12].

An adaptive type-2 fuzzy PID control (AIT2FPID) is designed to control the temperature of reactor tank by using 
a heat exchanger system. AI2FPID designed based on a PID algorithm performs the reasoning through calculating the error and error derivative of the system by using type- 2 fuzzy inference rules and adjusts the PID parameters by fuzzy rules. AI2FPID technique achieved smooth responses with best disturbance rejection in comparison to classical PID and MPC [13]. Novel scheme of Neural network model predictive control NNMPC with fuzzy control. The designed scheme is suitable to control different classes of process control such as distillation columns, boilers, and reactors, etc. The advantage of the combined NNMPC with fuzzy control is that it is not a linear-model-based strategy and the control input constraints are directly included into the controller synthesis. The disadvantage for this method is the complexity of design and time consuming to create their scheme [14]. Optimization of proportional integral fuzzy logic controller (PI-FLC) designed based on the use of a finite-dimensional approximate model. Different case studies been investigated based on changes in the process temperature from $25 \mathrm{C}^{0}$ to $35 \mathrm{C}^{0}$ and $25 \mathrm{C}^{0}$ to $50 \mathrm{C}^{0}$ respectively. The developed PI-FLC has demonstrated improvement in term of faster reach to the set point and disturbance rejection as compared to the classical controller [15]. The soft computing strategy using LabVIEW to design Fuzzy Logic Control (FLC) for a physical heat exchanger process. FLC designed based on first order plus dead time FOPDT process identification of the heat exchanger. The LabVIEW has been chosen because it provides enhanced graphical view and easier to implement to the real-time experimental. The performance indices show the effectiveness of the designed FLC control with better tracking capability [16]. The Fuzzy C-Means clustering algorithm is used with different types of fuzzy rules applied for Third Order Plus Dead Time (TOPDT) Heat Exchanger system. These types of fuzzy rules are fuzzy Mamdani and fuzzy Takagi-Sugeno. They compared together after implementation to heat exchanger system and Mamdani achieved superior performance. The simulation results confirm that fuzzy control is one of the possibilities for successful control of heat exchangers. This strategy is designed based on nonlinear model [17]. Fuzzy proportional integral derivative controller designed based on tuning the triangular rules by genetic algorithm (FPID-GA). Fitness functions associated with the system's performance indices include integral error and overshoot. The simulation studies investigated by considering a model of an induction motor control system and a higher order numerical model. However the method gives promised results but complex to design their rules [18].

This work focuses on a fuzzy logic combined with PD controller structure and compared with conventional PI controller to demonstrate and investigate the performance effect that applied for Physical model and SOPDT model. The paper is organized as follows. Section 2 presents the dynamic modelling of the heat exchanger. Section 3 describes the control design structure of the conventional Proportional Integral Derivative (PID) control and describes the Fuzzy proportional derivative (FPD) controller. In Section 4, simulation and experimental results regarding the control of the heat exchanger plant are discussed. Finally, the conclusion is presented.

\section{Mathematical Modelling of Heat Exchanger}

\section{A. Dynamic Model of Heat Exchanger (Physical Model)}

There are several varieties of heat exchangers used in many comfort and industry applications for heating and cooling fluids. The temperature control system of heat exchanger in district heating is a complex process control system whose properties are large heat inertia, slow time varying and so on. The system is shown in figure 1 .

The heat exchanger system, actuator, valve, sensor are mathematically modeled using the available experimental data. The heat flow into the tube is the difference between the heat from the hot liquid incoming and the heat flowing out to the product liquid [19][20]. The resulting equations are as below:

$$
\begin{gathered}
\dot{T}_{c o}(t)=\frac{w_{c}}{\rho_{c} V_{c}}\left(T_{c i}(t)-T_{c o}(t)\right)+\frac{U_{c} A_{c}}{\rho_{c} V_{c} C_{p c}}\left(T_{h o}(t)-\right. \\
\left.T_{c o}(t)\right) \\
\dot{T}_{h o}(t)=\frac{w_{h}}{\rho_{h} V_{h}}\left(T_{h i}(t)-T_{h o}(t)\right)+\frac{U_{h} A_{h}}{\rho_{h} V_{h} C_{p h}}\left(T_{c o}(t)-\right. \\
\left.T_{h o}(t)\right)
\end{gathered}
$$

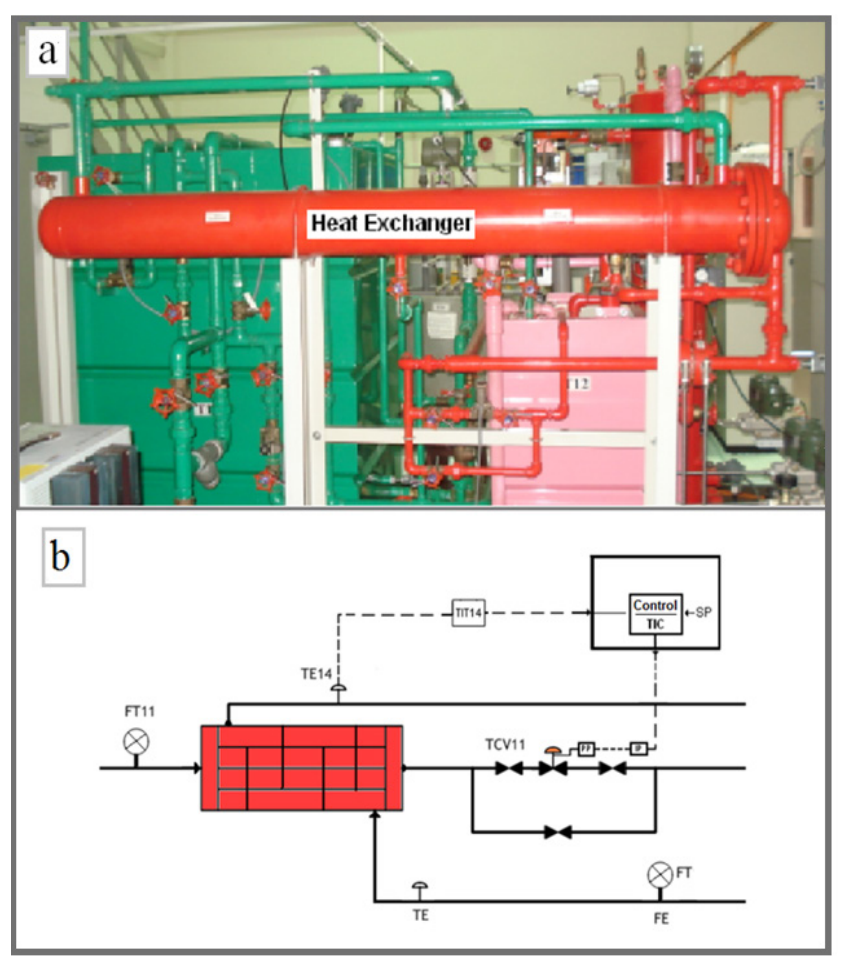

Figure 1. (a) The real power plant heat exchanger, (b) Power plant heat exchanger control scheme. 
where $T_{c i}, T_{c o}, T_{h i}, T_{h o}$ inlet and outlet cold and hot fluid temperature ${ }^{\circ} \mathrm{C}, w_{c}, w_{h}$ is mass flow rate of cold and hot fluid $\mathrm{kg} / \mathrm{sec}, C_{p c}, C_{p h}$ is the heat capacity of cold and hot fluid $\mathrm{J} / \mathrm{kg} .{ }^{\circ} \mathrm{C}, \rho_{c}, \rho_{h}$ the density of cold and hot fluid $\mathrm{kg} / \mathrm{cm}^{3} \quad V_{c}, V_{h}$ : volumes $\mathrm{cm}^{3}, A_{c}, A_{h}$ the heat transfer surface area of cold and hot fluid $\mathrm{cm}^{2}, U_{c}, U_{h}$ the heat transfer coefficient of cold and hot fluid $W / \mathrm{cm}^{2} C^{0}$. The Heat Exchanger plant specifications are listed in the Appendix Table 3.

\section{B. Second Order Plus Dead Time Model (SOPDT Model)}

Smith [22] has reported method to derive a SOPDT model based on two points of the fraction response of the system at $20 \%$ and $60 \%$. The prediction model is as the following:

$$
G(S)=\frac{k \cdot e^{-t_{0}}}{\left(\tau_{1} S+1\right)\left(\tau_{2} S+1\right)}
$$

where, $\mathrm{k}$ is the process gain, $\mathrm{t}_{0}$ is the process dead time, $\tau_{1}=\tau \xi+\tau \sqrt{\xi^{2}-1}, \tau_{2}=\tau \xi+\tau \sqrt{\xi^{2}-1}$.

\section{Heat Exchanger Control Design}

\section{A. Proportional Integral Derivative (PID) Controller}

A Proportional Integral Derivative (PID) controller has ability to improve both steady state and transient response of the system in the same time. The PID controller has three terms; the proportional term $\mathrm{P}$ corresponding to proportional control, the integral term I giving a control action that is proportional to the time integral of the error. Finally the derivative term $\mathrm{D}$ proportional to the time derivative of the error. The general PID controller equation is described as:

$$
\frac{U(s)}{E(s)}=K_{p}\left(1+\frac{1}{T_{i} s}+T_{d} s\right)
$$

where $K_{p}$ is a proportional gain of the controller and it will have effect for reducing the rise time, but never eliminate the steady-state error. $T_{i}$ is the integral time that it will have effect for eliminating the steady-state error, but it may make the transient response worse. Next is a derivative time $T_{d}$ will have effect for increasing the stability of the system [23]. Based on the characterization of Ziegler-Nichols by tangent method of the heat exchanger response PID controller values are $K_{P}=5, T_{i}=24$ sec, and $T_{d}=6 \mathrm{sec}$.

\section{B. Fuzzy Proportional Derivative (FPD) Controller}

Fuzzy logic is an innovative technology that allows the description of desired system behavior using every day spoken language [24]. Fuzzy logic usually derives into three stages. They are Fuzzification, Fuzzy Inference and Defuzzification. In a typical application, all three stages must be employed. Block diagram of fuzzy logic mechanism is as in Figure 2.

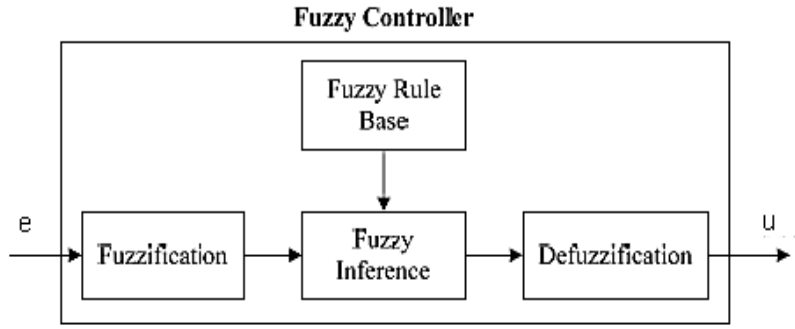

Figure 2. Fuzzy logic block diagram.

Fuzzy proportional derivative (FPD) control developed is a multi-input single output controller model. The inputs are error $(\mathrm{E})$ and derivative error (DE). Output is a signal control (U). Fuzzy logic controller can provide desirable both small signal and large signal dynamic performance at same time [25]. The structure of the FPD control that has been designed for shell and tube heat exchanger is represented by Figure 3 .

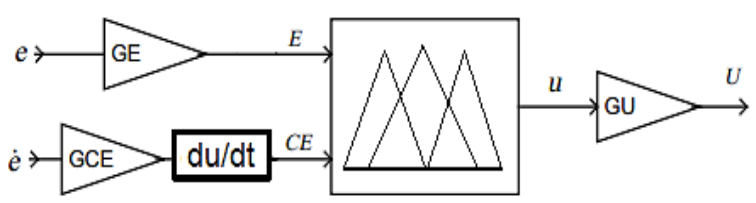

Figure 3. The Fuzzy proportional derivative (FPD) controller structure.

Structure of fuzzy-PD rules are shown in Table 1. The linguistic terms for error are: NE (negative error), ZE (zero error) and PE (positive error); for derivative error are: NLDE (Negative Large Derivative Error), NSDE (Negative Small Derivative Error), ZDE (Zero Derivative Error), PSDE (Positive Small Derivative Error), PLDE (Positive Large Derivative Error) and for output are: VL (Very low), L (Low), M (Medium), H (High), VH (Very High). The membership functions for input and output are triangular type. The structure of FPD controller table realized in Matlab/Simulink is presented in Table 1.

Table 1. Structure of fuzzy-PD controller rule table

\begin{tabular}{|c|c|c|c|}
\hline NLDE & NE & ZE & PE \\
\hline NSDE & VL & L & L \\
\hline ZDE & L & M & H \\
\hline PSDE & L & M & VH \\
\hline PLDE & $\mathrm{M}$ & $\mathrm{H}$ & VH \\
\hline
\end{tabular}

\section{Results and Discussion}

In practice, the model parameters for a FOPDT or SOPDT models are commonly gained from experiment 
transient response. These techniques had been used for a wide range of process control studies to its simplicity to use and been most effective way to get faster results through real-time processes. The temperature set point in the hot tube is chosen to be $40^{\circ} \mathrm{C}$.

In Figure 4, the PID control based on the Physical model shows similar trend to the PID control based real time experiment. However, FPD control achieved better performance without overshoot and faster trend compare to the both PID control cases. The Physical model shows that it able to represent the heat exchanger plant dynamics due to the matching of the PID controller responses in both cases.

In Figure 5, the PID control based on SOPDT model shows less overshoot than the PID control based real time experiment. However, FPD control achieved better performance without overshoot and faster trend compare to both PID control cases. The details regarding performance index IAE, overshoot effect and reaching time to the setpoint are presented in Table 2.

In case of PID controls, for Physical model is more accurately than the SOPDT model. because it provides key information as to the nature and characteristic of the real system dynamics which is vital for the investigation and prediction of the system operation. That means the Physical model able to represent the heat exchanger plant dynamics. However, the FPD control gives a slight enhancement with SOPDT model.

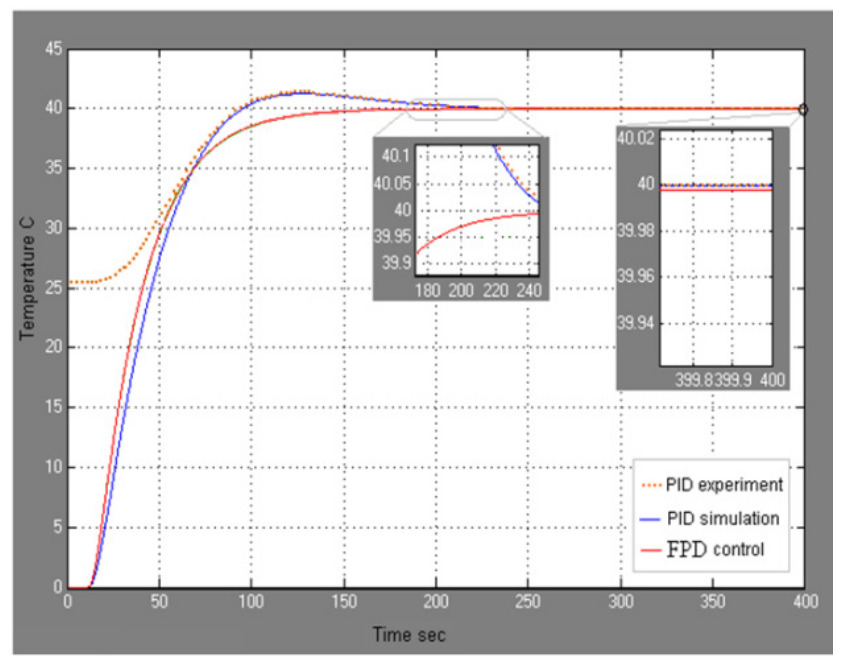

Figure 4. Results of PID Experiment, PID Simulation, and FPD controller (Physical model)

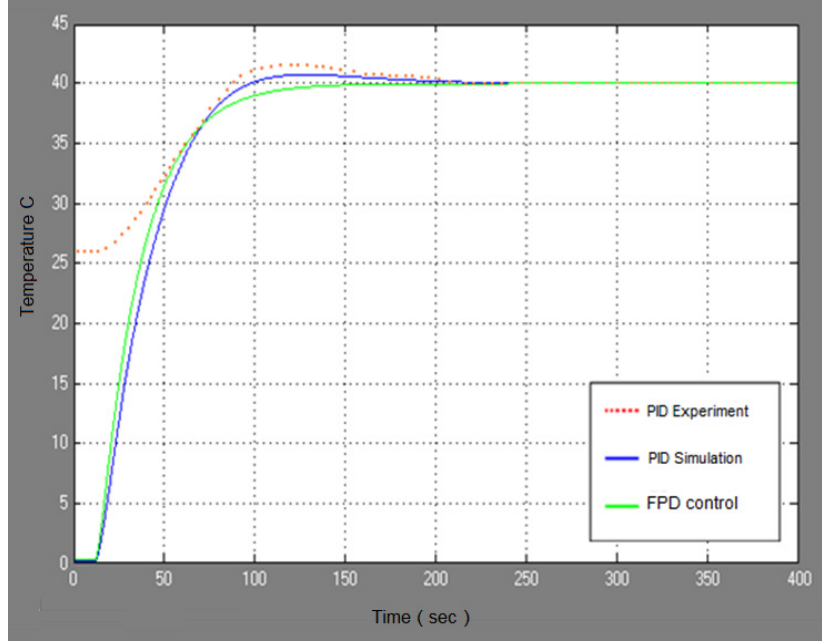

Figure 5. Result of PID Experiment, PID Simulation, and FPD control (SOPDT Model).

Table 2. Compare between PID Experiment, PID simulations, and FPD controller

\begin{tabular}{|c|c|c|c|c|}
\hline Controller & IAE & overshoot & $\begin{array}{c}\text { Rise } \\
\text { time }\end{array}$ & $\begin{array}{c}\text { Settling } \\
\text { time }\end{array}$ \\
\hline PID Experiment & 513 & $3.57 \%$ & $58 \mathrm{sec}$ & $237 \mathrm{sec}$ \\
\hline $\begin{array}{c}\text { PID Simulation } \\
\text { Physical model }\end{array}$ & 1908 & $3.42 \%$ & $53.4 \mathrm{sec}$ & $233 \mathrm{sec}$ \\
\hline $\begin{array}{c}\text { PID Simulation } \\
\text { SOPDT model }\end{array}$ & 1774 & $3 \%$ & $51 \mathrm{sec}$ & $220 \mathrm{sec}$ \\
\hline $\begin{array}{c}\text { FPD control } \\
\text { Physical model }\end{array}$ & 1766 & $0 \%$ & $50 \mathrm{sec}$ & $183 \mathrm{sec}$ \\
\hline $\begin{array}{c}\text { FPD control } \\
\text { SOPDT model }\end{array}$ & 1743 & $0 \%$ & $49.3 \mathrm{sec}$ & $181 \mathrm{sec}$ \\
\hline
\end{tabular}

Based on Table 2, the comparison shows that of models under the FPD controller are better with no overshoot and less settling time around $180 \mathrm{sec}$ in comparison to the PID controller. The settling time based PIDs registered with more than $220 \mathrm{sec}$. However, the response of FPD physical model can reach model exactly at 50 second, no overshot, no steady state error and has settling time 183 second.

\section{Conclusion}

This paper discussed the modeling and control of power plant heat exchanger system. From results and discussion, PID control for Physical model more matching with real time than SOPDT model. That means the Physical model able to represent the heat exchanger plant dynamics. However, the FPD control gives a slight enhancement with SOPDT model. For that, FPD controller is more suitable to control the heat exchanger process instead of PID control. 


\section{Appendix}

Table 3. Specifications of the Heat Exchanger System

\begin{tabular}{|c|c|l|}
\hline Symbol & Parameter Description & \multicolumn{1}{|c|}{ Value } \\
\hline$A_{c}$ & $\begin{array}{c}\text { Heat transfer surface area of } \\
\text { cold fluid }\end{array}$ & $9443 \mathrm{~cm}^{2}$ \\
\hline$A_{h}$ & $\begin{array}{c}\text { Heat transfer surface area of } \\
\text { hot fluid }\end{array}$ & $6768 \mathrm{~cm}^{2}$ \\
\hline$T_{c i}$ & Inlet cold fluid temperature & $26 C^{0}$ \\
\hline$T_{h i}$ & Inlet hot fluid temperature & $60 C^{0}$ \\
\hline$\rho_{c}$ & Density of cold fluid & $\begin{array}{l}9.9 \\
\times 10^{-4} \mathrm{~kg} / \mathrm{cm}^{3}\end{array}$ \\
\hline$\rho_{h}$ & Density of cold hot fluid & $\begin{array}{l}9.8 \times 10^{-4} \mathrm{~kg} \\
/ \mathrm{cm}^{3}\end{array}$ \\
\hline$w_{c}$ & Mass flow rate of cold fluid & \multicolumn{2}{|c|}{$\mathrm{kg} / \mathrm{sec}$} \\
\hline
\end{tabular}

\section{REFERENCES}

[1] Oravec J, Bakošová $\mathrm{M}$, Mészáros $\mathrm{A}$, Míková $\mathrm{N}$. Experimental investigation of alternative robust model predictive control of a heat exchanger. Applied Thermal Engineering, 2016; 105:774-782.

[2] Zhang X, Lu K, Li X, Xiong X. Research on the modeling and simulation of shell and tube heat exchanger system based on MPCE. $20124^{\text {th }}$ International Conference on Intelligent Human-Machine Systems and Cybernetics (IHMSC), pp. $328-331 ; 2012$.

[3] Vilanova R. IMC based Robust PID design: Tuning guidelines and automatic tuning. Journal of Process Control, 2008; 18(1):61-70.

[4] Lincoln R, Prakash J. Multiple model and neural based adaptive multi-loop PID controller for a CSTR process. World Academy of Science, Engineering and Technology, International Journal of Computer, Electrical, Automation, Control and Information Engineering, 2010; 4(8): 1270-1275.

[5] Manikandan R, Vinodha R, Lincoln SA, Prakash J. Design and simulation of model based controllers for $2 \times 2$ CSTR process. 2014 International Conference on Green Computing Communication and Electrical Engineering (ICGCCEE), pp. 1-7; 2014.

[6] Constantinescu, R. and Decatur, G. A. MRAC strategy for the temperature profile control of a Lime Kiln. Technical Papers of ISA 2001 Technology Update, pp. 1-6; 2001.

[7] Man C, Li J, Wang L. Chi Y. The fuzzy PID control system for superheated steam temperature of boiler. $6^{\text {th }}$ International Forum on Strategic Technology (IFOST), pp. 967-970; 2011.

[8] Shome A, Ashok SD. Fuzzy logic approach for boiler temperature \& water level control. International Journal of Scientific and Engineering Research, 2012; 3(6): 1-6.

[9] Imal E. CDM based controller design for nonlinear heat exchanger process. Turkish Journal of Electrical Engineering \& Computer Sciences, 2009; 17(2): 143-161.
[10] Manikandan R. Vinodha R. Multiple Model Based Adaptive Control for Shell and Tube Heat Exchanger Process. International Journal of Applied Engineering Research, 2016; 11(5):3175-3180.

[11] Arbogast J, Cooper DJ, Rice RC. Model-based tuning methods for PID controllers. Technical report 2010 Control Station, Inc. 2010, 1-10.

[12] Dulău M, Oltean S. Gligor A. Conventional control vs. robust control on heat-exchangers. Procedia Technology, 2015; 19: 534-540.

[13] Beirami H. Zerafat M. Self-tuning of an interval type-2 fuzzy PID controller for a heat exchanger system. Iranian Journal of Science and Technology Transactions of Mechanical Engineering, 2015; 39: 113-129.

[14] Vasičkaninová A, Bakošová M. Control of a heat exchanger using neural network predictive controller combined with auxiliary fuzzy controller. Applied Thermal Engineering, 2015; 89: 1046-1053.

[15] Maidi A, Diaf M, Corriou J. Optimal linear PI fuzzy controller design of a heat exchanger. Chemical Engineering and Processing: Process Intensification, 2008; 47(5): 938-945.

[16] Paul R, Shreesha C, Shinde S. LabVIEW Implementation of fuzzy logic controller for heat exchanger process. 2015 International Conference on Futuristic Trends on Computational Analysis and Knowledge Management (ABLAZE), 13-17, 2015.

[17] Vasičkaninová A, Bakošová M, Kmet'ová J. Fuzzy control of a heat exchanger using fuzzy c-means clustering algorithm, $41^{\text {st }}$ International Conference of Slovak Society of Chemical Engineering, 917-926, 2014.

[18] Juang YT, Chang YT, Huang CP. Design of fuzzy PID controllers using modified triangular membership functions. Information Sciences, 2008; 178(5):1325-1333.

[19] Emhemed AA, Mamat RB, Hanafi D. Mathematical modeling of industrial heat exchanger system. Applied Mechanics and Materials, 2012; 229:2122-2124.

[20] Emhemed AA. Development of heat exchanger performance using intelligence control. Universiti Tun Hussein Onn Malaysia. M.Sc. Thesis, 2010.

[21] Hanafi D, Than MNM, Emhemed AA, Mulyana T, Zaid AM, Johari AH. Heat exchanger's shell and tube modeling for intelligent control design. 2011 IEEE $3^{\text {rd }}$ International Conference on Communication Software and Networks, Xi'an, China, 37-41; 2011.

[22] Smith CA, Corripio AB. Principles and practice of automatic process control, $3^{\text {rd }}$ edition, Wiley Inc; 2006.

[23] Åström KJ. Control system design lecture notes for me 155a. Department of Mechanical and Environmental Engineering, University of California Santa Barbara; 2002.

[24] Jantzen J. Foundations of fuzzy control: a practical approach. Wiley and Sons Inc; 2013.

[25] Guo S, Peters L, Surmann H. Design and application of an analog fuzzy logic controller, IEEE Transaction on Fuzzy System, 1996; 4(4):429-438. 